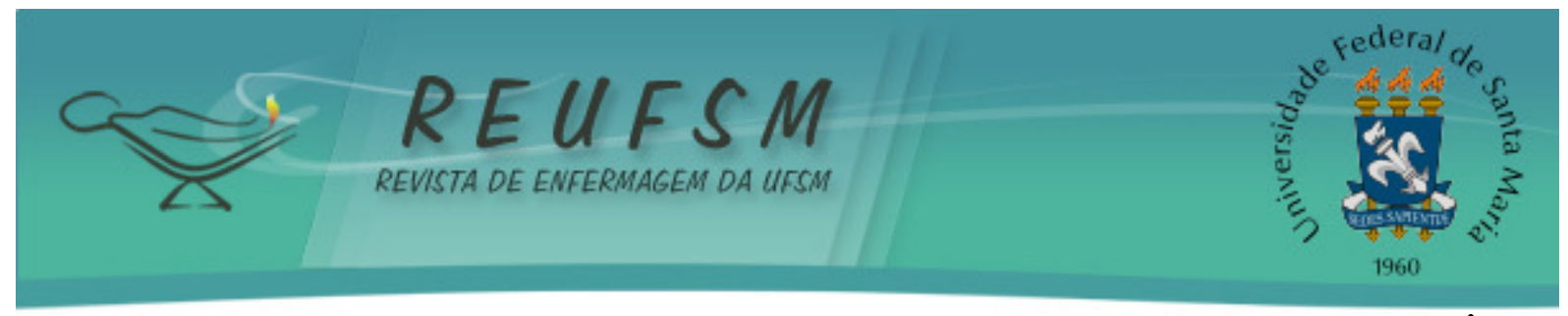

RELATO DE EXPERIÊNCIA

\title{
EDUCAÇÃO EM SAÚDE COM ESTOMIZADOS E SEUS FAMILIARES: POSSIBILIDADE PARA MELHOR QUALIDADE DE VIDA
}

\author{
HEALTH EDUCATION WITH YOUR FAMILY AND OSTOMIZED PATIENTS: CHANCE FOR \\ BETTER QUALITY OF LIFE
}

\section{EDUCACIÓN PARA SALUD CON OSTOMIZADOS Y SU FAMILIA: OPORTUNIDAD PARA UNA MEJOR CALIDAD DE VIDA}

\author{
Camila Fernandes Wild ${ }^{1}$ \\ Natalia Barrionuevo Favero ${ }^{2}$ \\ Cléton Salbego ${ }^{3}$ \\ Michele Gonçalves de Vale ${ }^{4}$ \\ Jonatan da Rosa Pereira da Silva ${ }^{5}$ \\ Tierle Kosloski Ramos
}

Doi: $10.5902 / 2179769220071$

RESUMO: Objetivo: relatar a experiência de enfermeiros frente à realização de ações educativas com pacientes estomizados e seus familiares em uma Estratégia Saúde da Família da Fronteira Oeste do Rio Grande do Sul. Método: relato de experiências acerca da realização de ações educativas com um grupo de pacientes estomizados e seus familiares, desenvolvido no período de seis meses, pela equipe multiprofissional da Estratégia Saúde da Família. A proposta educativa ocorreu sob uma perspectiva de roda de conversas, o que propiciou o compartilhamento de saberes científicos e populares entre os envolvidos. Buscou-se incentivar o cuidado de si e a participação da família no processo. Resultados: no grupo educativo foram abordados assuntos relativos à alimentação, sexualidade, autocuidado e autoimagem, além dos cuidados básicos com a estomia e manejo da bolsa coletora. Considerações Finais: a propostacontribuiu para a melhoria da qualidade de vida desses pacientes, minimizando dúvidas pertinentes surgidas naturalmente pela sua condição.

Descritores: Educação em saúde; Estomia; Autocuidado; Estratégia saúde da família; Enfermagem.

ABSTRACT: Aim: to report the nurses' experience with the realization of educational activities with ostomized patients and their families in a Family Health Strategy from the West Frontier of the Rio Grande do Sul. Method: experience report on the conduction of educational activities with a group of ostomized patients and their families, developed during the period of six months by the professional staff of the Family Health Strategy. The educational proposal happened under a perspective of conversation circles, which led to the sharing of scientific and popular knowledge among the participants. The aim was to encourage self-care and family participation in the process. Results: in the education

\footnotetext{
${ }^{1}$ Enfermeira. Mestranda pelo Programa de Pós Graduação em Enfermagem da Universidade Federal de Santa Maria. Santa Maria, Rio Grande do Sul, Brasil. E-mail: camilinhah@hotmail.com

${ }^{2}$ Enfermeira. Mestranda pelo Programa de Pós Graduação em Enfermagem da Universidade Federal de Santa Maria. Santa Maria, Rio Grande do Sul, Brasil. Email: nathybf@hotmail.com

${ }^{3}$ Enfermeiro. Mestre em Enfermagem. Sistema de Ensino Gaúcho. Santa Maria, Rio Grande do Sul, Brasil. Email: cletonsalbego@hotmail.com

${ }^{4}$ Enfermeira. Prefeitura Municipal de São Gabriel. São Gabriel, Rio Grande do Sul, Brasil. E-mail: micagdv@hotmail.com

${ }^{5}$ Discente de Enfermagem. Universidade Federal de Santa Maria. Santa Maria, Rio Grande do Sul, Brasil. Email: jonatanprd@gmail.com

${ }^{6}$ Discente de Enfermagem. Universidade Federal de Santa Maria. Santa Maria, Rio Grande do Sul, Brasil. Email: tierleramos@hotmail.com
} 


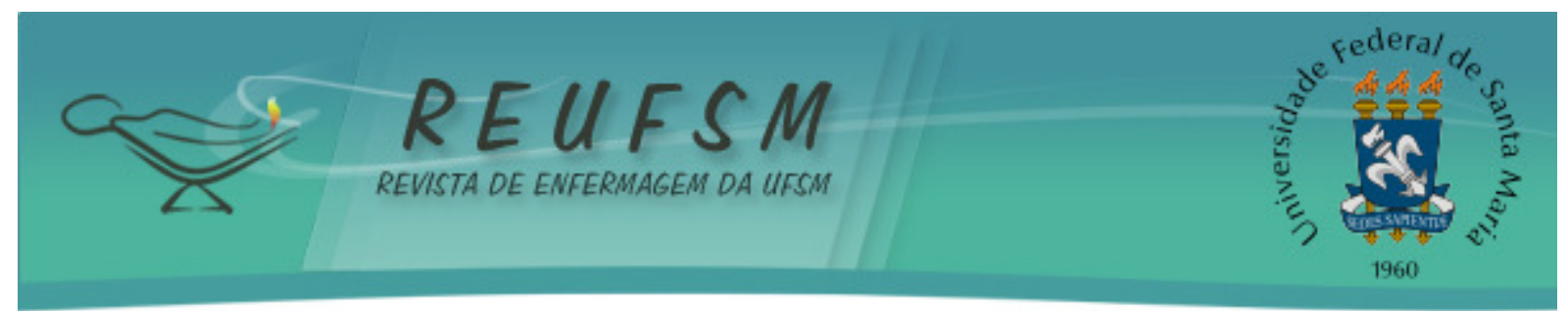

group issues related to food, sexuality, self-care and self-image were discussed, besides basic care with the stoma and management of the stoma bag. Final Remarks: the proposal has contributed to the improvement of patients' quality of life by clarifying relevant questions that arise naturally by their condition.

Descriptors: Health education; Ostomy; Self care; Family health strategy, Nursing.

RESUMEN: Objetivo: presentar la experiencia de las enfermeras en la realización de actividades educativas con pacientes ostomizados y sus familias en una Estrategia Salud de la Familia en la Frontera Oeste de Río Grande del Sur. Método: informe de experiencia sobre la realización de actividades educativas con pacientes ostomizados y sus familias, desarrollado en seis meses por profesionalesde la Estrategia Salud de la Familia. La propuesta se efectuóa través de ruedas de conversaciones, lo que permitió el intercambio de conocimientos científicos y populares. Se fomentó el autocuidado y la participación de la familia en el proceso. Resultados: se abordaron temas relacionados con la alimentación, la sexualidad, el cuidado personal y la propia imagen, también el cuidado y la gestión de la bolsa de recogida de ostomía básica. Consideraciones finales: la propuesta contribuye paramejorar la calidad de vida de los pacientes, reduciendo las dudas planteadas por su condición.

Descriptores: Educación en salud; Estomía; Autocuidado; Estrategia de salud familiar; Enfermería.

\section{INTRODUÇÃO}

Estoma intestinal tem como significado a exteriorização de uma porção intestinal por uma abertura através da cavidade abdominal que, dependendo do segmento exposto, terá diferentes denominações, por exemplo, colostomia e ileostomia, podendo ser tanto permanente como temporária. Essas intervenções aumentam a expectativa de vida do paciente, porém trazem mudanças para ele e seus familiares, ligadas as limitações de ter um estoma. ${ }^{1}$

Segundo dados do Instituto Nacional do Câncer (INCA), o câncer de cólon e de reto se constitui na terceira causa mais comum de acometimento, em nível mundial, de homens e a segunda em mulheres, com aproximadamente 2,4 milhões de pacientes. Estima-se, para 2016, no Brasil, o aumento de 16,84 casos a cada 100 mil homens e 17,10 para cada 100 mil mulheres. ${ }^{2}$ Entre as opções de tratamento, a estomia é o procedimento cirúrgico em que se realiza a exteriorização do cólon, possibilitando restabelecer o trânsito intestinal. $^{3}$

Uma estomia se apresenta, na maioria dos casos, como um limitador da qualidade de vida, visto que os pacientes se deparam com algumas dificuldades. 0 corpo do paciente apresenta alterações anatômicas e fisiológicas, tais como a falta da função esfincteriana e a presença de um estoma na região abdominal, que passa a ser o local para as eliminações intestinais. Viver nesta condição tem consequências prejudiciais à autoimagem, à autoestima e ao convívio social do paciente, podendo gerar conflitos, preocupações e anseios. $^{4}$

A abordagem desses pacientes nos serviços de saúde necessita ser diferenciada e acolhedora, surgindo, então, as ações de educação em saúde. Por meio delas é possível que a equipe multiprofissional planeje a assistência podendo, assim, ter um papel importante na (re)adaptação fisiológica, psicológica e social da pessoa estomizada, contribuindo para a melhoria da qualidade de vida dessas pessoas. ${ }^{5}$

A educação em saúde, na enfermagem, é considerada uma estratégia fundamental para o desenvolvimento de uma assistência de qualidade, quando utilizada como meio de 


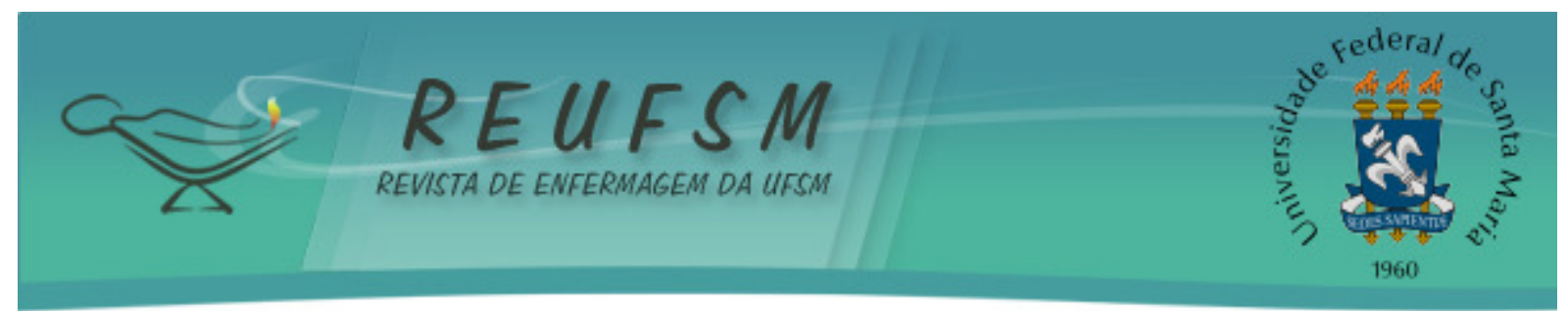

comunicação e problematização da realidade. A partir de ações educativas, é possível desenvolver a troca de saberes e práticas, em que o saber profissional (científico) e o senso comum (popular) se unem em benefício de um objetivo. Com isso, tem-se a construção de indivíduos mais críticos, reflexivos e conscientes. Nesse ínterim, o enfermeiro, além de desenvolver o papel de cuidador, é também um educador, tanto para o paciente quanto para a família. ${ }^{6-7}$

Para tanto, a enfermagem precisa conhecer a realidade do usuário, tentando resgatar esse indivíduo como cidadão participante do seu próprio processo de cuidado, por meio do diálogo, promovendo a (re)construção de saberes e possibilidades de mudança/transformação da realidade, culminando em uma interação mútua, verdadeira, horizontal e humanizada. ${ }^{8}$ Os preceitos da educação em saúde corroboram, neste estudo, por ela se caracterizar como:

Uma prática social cujo processo contribui para a formação da consciência crítica das pessoas a respeito de seus problemas de saúde, a partir da sua realidade, estimulando a busca de soluções e organização para uma ação individual e coletiva. 9:19

Partindo do exposto, o estudo objetiva relatar a experiência de enfermeiros frente à realização de ações educativas com pacientes estomizados e seus familiares em uma Estratégia Saúde da Família (ESF)da Fronteira Oeste do Rio Grande do Sul.

\section{METODOLOGIA}

Trata-se de um relato de experiência sobre a realização de grupos educativos com pacientes estomizados em um município da Fronteira Oeste do Rio Grande do Sul, desenvolvidos pela equipe de enfermagem de uma ESF. A ESF tem seu funcionamento de segunda à sexta-feira, para a população em geral. Nessa unidade de saúde, há o desenvolvimento de programas vinculados ao Ministério da Saúde (MS), que preveem ações educativas usando metodologias grupais para pacientes com doenças crônicas, tais como hipertensos e diabéticos; gestantes e puérperas e pacientes/pessoas com feridas. Assim, inserem-se os grupos educativos com pacientes estomizados. Essa iniciativa foi desenvolvida devido ao déficit de autocuidado, autoestima, desconhecimento sobre sua patologia primária, aspectos inerentes à sexualidade e nutrição, entre outros, identificados durante as consultas de enfermagem.

As atividades perpassaram seis meses, tendo início em março de 2014. Para a operacionalização dos encontros, primeiramente,foi realizado o levantamento dos prontuários dos pacientes acompanhados pela unidade de saúde. Por meio de contato telefônico foi realizado o convite, informando data, hora e local para o encontro. Durante os seis meses foram desenvolvidos dois grupos/encontros com duração de cerca de três horas, nas dependências da ESF, contando com a participação da equipe multidisciplinar (médico, enfermeiros, técnicos de enfermagem, psicóloga, nutricionista e agentes de saúde). Os enfermeiros atuaram como mediadores das ações educativas.

No primeiro momento, foram realizadas apresentações e todos os participantes tiveram a oportunidade de estabelecer diálogos e socializar informações pessoais. Foram expressos os objetivos do grupo, informando a finalidade de proporcionar o compartilhamento de experiências e realização de orientações, minimizando dúvidas em relação ao processo de viver com estomia.

No segundo momento, as orientações iniciaram com o esclarecimento de aspectos nutricionais; foram explicados os fatores referentes aos hábitos alimentares, como redução 


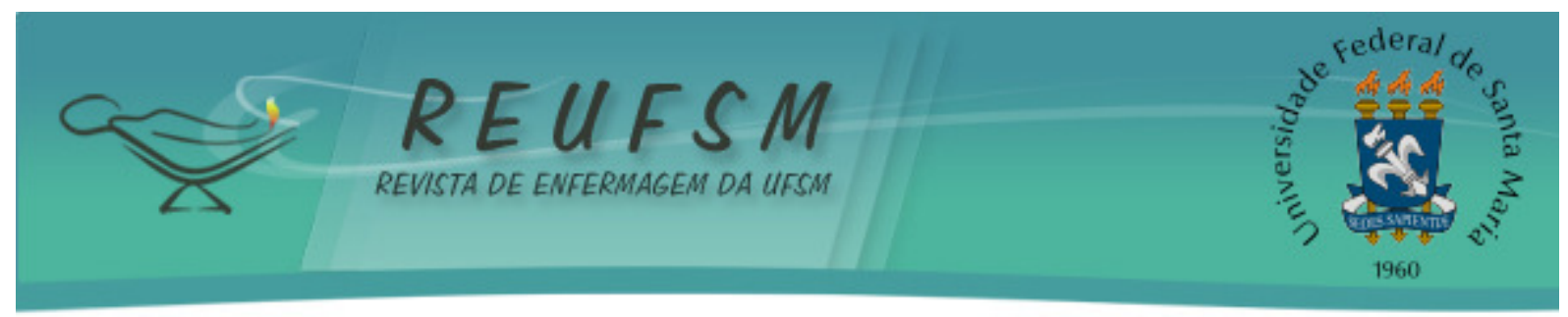

e/ou substituição de componentes da dieta. Consecutivamente, abordou-se a sexualidade, e foi perceptível o impacto que a estomia pode causar sobre a imagem corporal dos indivíduos, sua autoestima, as relações entre os pares e a família, gerando déficit de autocuidado. Visando aos cuidados necessários com a bolsa coletora e com a pele, foram abordados aspectos referentes à higienização do estoma e cuidados com a integridade da pele e risco de infecção.

No terceiro momento, abriu-se espaço para conversas, incentivando a troca de vivencias após a socialização/captura de informações.

\section{RESULTADO E DISCUSSÃO}

O serviço possuía um total de 27 pacientes cadastrados no programa de estomizados da ESF, o que corresponde ao número de usuários que recebem materiais e atendimento especializado no local. Desse total, foi possível entrar em contato com 18, entretanto, 12 compareceram ao encontro (oito homens e quatro mulheres), alguns acompanhados de seus familiares, totalizando 20 participantes.

Por meio de conversas informais, foi possível conhecer cada paciente/participante, dentre os quais sete eram casados, três solteiros e dois viúvos. Quanto à idade, os indivíduos apresentaram entre 45 e 65 anos. Com relação a escolaridade, três não alfabetizados, sete com ensino fundamental incompleto e dois com ensino superior completo. Como profissão, todos informaram ser aposentados e/ou do lar. Esses pacientes passaram por internação no hospital filantrópico do município. O tempo de utilização da colostomia variou: oito pacientes faziam uso entre seis a nove meses, os demais referiram a utilização há mais de um ano. Os motivos que justificaram o uso foram: seis pacientes com tumor retal; três com estreitamento do canal retal e três com processo inflamatório resultante de procedimento cirúrgico.

$\mathrm{Na}$ operacionalização do grupo, o primeiro momento ocorreu com a preparação do local, no qual as cadeiras foram distribuídas de forma circular de modo a promover a interação "face a face" e fluência do diálogo. No segundo momento, foram recebidos os pacientes e seus familiares de modo acolhedor, visando estabelecer o vínculo, propiciando um espaço para conversas informais.

Dispor o grupo em roda de conversa permite instituir o diálogo, o posicionamento crítico e o incentivo à liberdade dos sujeitos, como base fundadora do que chamamos de processo de conscientização.Este se caracteriza por um processo de formação, sustentado por uma dialogicidade permanente, permitindo aos educandos (pacientes estomizados) pronunciarem o mundo, mediatizados por esse mesmo mundo, entendendo-o, descodificando-o e, quando necessário, intervindo sobre ele para transformá-lo. ${ }^{10-12}$

Por isso, entendemos esse contexto como uma pedagogia, que necessita proporcionar uma educação problematizadora (em oposição a uma educação bancária), cuja prática educativa progressista desafia os pacientes e seus familiares em suas curiosidades, anseios e mitos. Também exige dos educadores (profissionais) uma redefinição do seu papel de ensinante, transformando-os em ensinantes-aprendentes, uma vez que "ensinando uns e aprendendo outros, todos aprendem e ensinam, sem que isso signifique serem iguais, ou que quem ensina não aprende e quem aprende não ensina". 11:141

Para isso, é preciso compreender que ensinar não é transferir conhecimentos, mas sim criar possibilidades para produção e construção, despertando curiosidades, para que os indivíduos se tornem criativos, críticos e reflexivos. ${ }^{12}$ No contexto em estudo, a utilização e aplicação dos preceitos teóricos de Freire permitem, aos profissionais de saúde, desenvolver uma dinâmica de trabalho que desprenda possibilidades de tornar os pacientes estomizados mais autônomos, capazes de gerenciar seus medos, anseios e estigmas, sua 


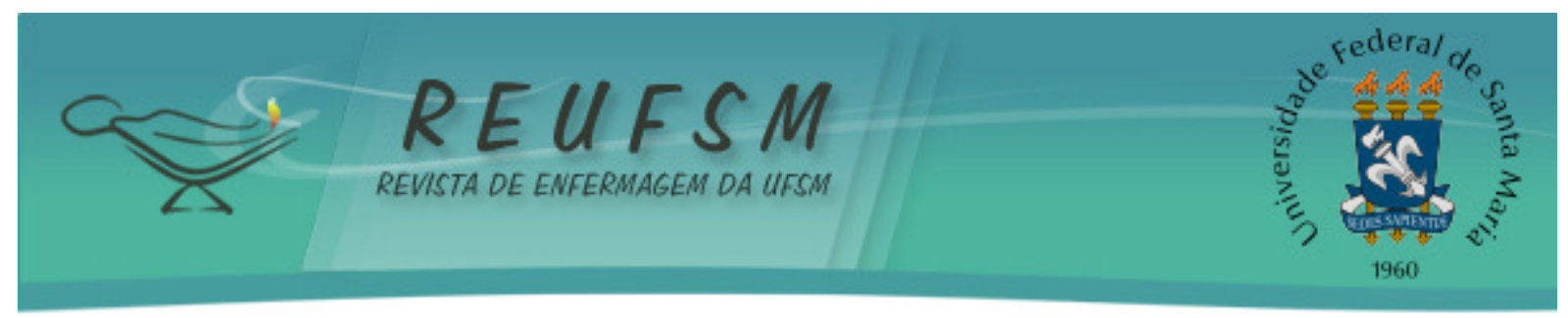

autoestima e autoimagem, a partir da reflexão sobre o contexto, troca de experiências e posicionamento crítico.

No terceiro momento, iniciaram-se as orientações preparadas para o encontro. Foram abordados os cuidados com a alimentação e os alimentos que afetam o trato gastrointestinal. Pode-se perceber que, em geral, os pacientes não dão a devida importância para sua alimentação, apesar de, por meio desse cuidado, ser possível regularizar o volume de fezes, diminuir odor e gases. A maioria das pessoas estomizadas altera o seu modo de vida: a alimentação e o funcionamento intestinal possuem importantes relações, pois a qualidade e a quantidade de alimento interferem no volume e na consistência das fezes. ${ }^{13}$

A estomia acarreta restrições alimentares e existe a necessidade da realização de dietas rigorosas. Em alguns casos, consiste em se abster de alguns alimentos que causam gases com o objetivo de evitar flatulência excessiva, além de complicações como diarreia. ${ }^{14}$ Essa restrição alimentar é um fator que influencia no modo como o paciente se relaciona com seu corpo e com a doença. Ainda, eles possuem medo de se alimentar em público, provocando a redução do prazer da alimentação e, consequentemente, o isolamento ou exclusão social. ${ }^{15}$

Cuidados com a bolsa coletora e com a pele também foram discutidos no encontro. Os pacientes relataram como realizavam a limpeza da pele e da bolsa, momento em que expuseram suas facilidades e dificuldades e socializaram com os demais participantes estratégias para o melhor manejo da bolsa coletora. Esse momento de troca de saberes permitiu o acesso a diferentes cuidados com a estomia, à luz do senso comum e das vivências singulares de cada participante. Assim, possibilitou a instrumentalização dos profissionais que participavam do grupo, por meio do acesso à informação popular, que potencializará as futuras orientações a pacientes que vivem com estoma.

Os cuidados podem influenciar a médio/longo prazo o desenvolvimento de complicações tardias, principalmente dermatites irritativas, decorrentes do contato constante do fluído intestinal com a pele em torno do estoma. A prevenção de lesão na pele periestoma deve ser a meta fundamental a ser atingida durante os cuidados. A higiene é importante para manutenção dos cuidados com a estomia. O suporte para isso é elencar práticas educativas capazes de desenvolver orientações positivas face aos cuidados possíveis de desvelarem anseios. ${ }^{8}$

Estabelecer um cuidado adequado com a bolsa no cotidiano é algo ontológico, pois tem um significado muito detalhado para os pacientes. As preocupações advêm dos pequenos atos e se estendem até ao bem-estar e à vida dos familiares, seja durante a troca da bolsa ou limpeza da pele. ${ }^{3}$

A sexualidade também foi tema de discussão, visto que a maioria dos participantes possuía receios e dúvidas. Em geral, os pacientes retomaram as relações sexuais com seus parceiros(as), porém referiram alteração devido à diminuição da autoestima, autoimagem e a vergonha ou medo da não aceitação pelo parceiro(a) em função da presença do estoma como parte do corpo.

$\mathrm{Na}$ sexualidade, podem surgir dificuldades causadas pela alteração na imagem corporal, às vezes, sujeita à perda da libido e impotência. Essas dificuldades e enfrentamentos decorrem do estado psicológico de cada paciente, a vergonha e o sentimento de estar sujo, faz com que o medo da rejeição seja intenso. Nos seres humanos, isso é reflexo da construção, ao longo da vida, de uma imagem de seu próprio corpo que está ligada a costumes e ao o ambiente em que vivem. A imagem corporal é, historicamente, ligada a conceitos de juventude, beleza, vigor, integridade e saúde. ${ }^{13-16}$ 


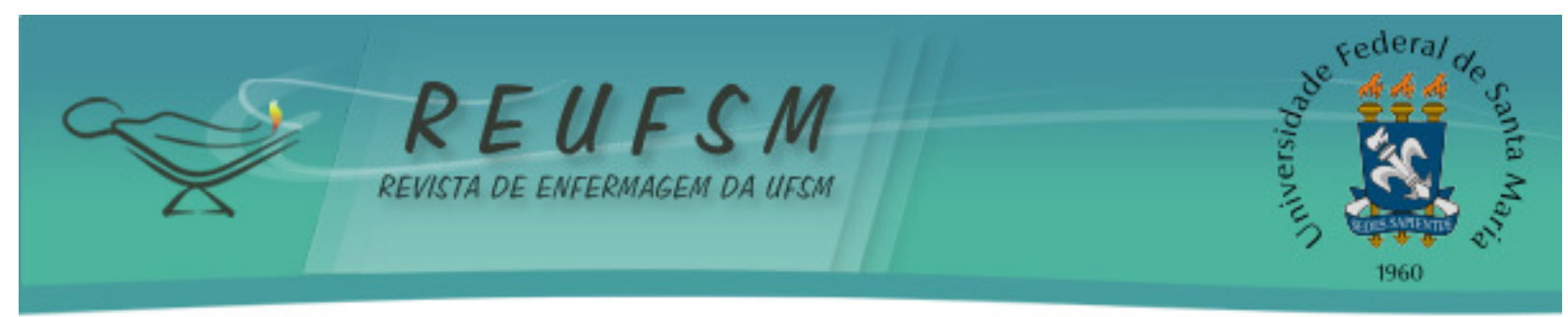

A partir dos grupos e discussões geradas sobre os temas levantados, incidiram as trocas de experiências, esclarecimento de dúvidas, realização de perguntas e respostas, minimizadas, muitas vezes, pela troca entre os próprios pacientes/participantes.

Cada paciente possui sua singularidade, seu momento, sua forma de enfrentamento e adaptação à nova condição, por vezes, vivendo com sofrimento, dor, incertezas, mitos e medos. Entretanto, a ESF assim como a equipe multiprofissional, incluindo o enfermeiro, são indispensáveis no acompanhamento aos estomizados, à medida que estes pacientes necessitam de apoio para enfrentar as transformações resultantes da estomia e a perda de parte de um sistema que irá privá-lo do controle fecal e da eliminação de gases. ${ }^{17}$

Dessa forma, a realização de grupos com pacientes estomizados se torna importante, pois pode mostrar os significados que a presença do estoma adquire de acordo com a experiência de vida de cada um. Aos pacientes, o conhecimento e esclarecimento de dúvidas e a troca de vivências oportunizam o (re)pensar de suas atitudes. Já para os profissionais, faz-se necessário conhecer e compreender as pessoas estomizadas na sua temporalidade, mediante a interpretação dos sentimentos expressos, incluindo as manifestações verbais de suas emoções. ${ }^{3,6}$

Compreende-se, então, que profissionais de saúde podem colaborar com a qualidade de vida desses pacientes, por meio de estratégias e ações em saúde, como o desenvolvimento de grupos que discutam, além do enfoque da doença, uma perspectiva que os auxilie na tomada de decisões e verbalizem sentimentos/enfrentamento acerca das mudanças na sua imagem corporal. ${ }^{18}$

\section{CONSIDERAÇÕES FINAIS}

Acredita-se que a realização de ações de educação em saúde contribui para a melhoria na qualidade de vida dessa clientela. Isso ocorre por meio de um adequado planejamento da assistência, que inclua o apoio psicológico e a educação em saúde, e que potencialize as aptidões da pessoa para o autocuidado, o que tem papel decisivo na adaptação com as alterações anatômicas, fisiológicas, psicológicas e sociais da pessoa estomizada e seus familiares.

Ao efetivar práticas que possibilitem a interação entre profissionais e pacientes, espera-se estimular a autonomia, autoconhecimento, autocuidado, debate sobre valores, descobertas de sentimentos e amenizar tabus.

Finalmente, almeja-se, com esta proposta de trabalho, oportunizar um exercício reflexivo que traga um olhar/fazer diferenciado na assistência ao paciente estomizado, por meio da articulação interinstitucional, da interdisciplinaridade, da instrumentalidade de ações de capacitação, da mobilização para construção de práticas emancipatórias e da transversalidade do compromisso com a promoção da saúde. A prática se desvelou uma potencial geradora de orientações para uma melhor qualidade de vida aos participantes, à medida que foram incentivados a viver de forma saudável com estomia.

A partir das práticas desenvolvidas, foi possível identificar que a realização de grupos educativos apresenta potencialidades emancipadoras. Contudo, novas estratégias necessitam ser utilizadas pelas equipes de saúde, em especial de enfermagem, com vistas a desenvolver meios eficazes e permanentes para promover a educação das pessoas que vivenciam a estomia. Assim, acredita-se que a enfermagem necessita investir na construção de tecnologias, tais como cartilhas, folders, vídeos, entre outros, que promovam o acesso facilitado à informação de qualidade, acerca dos cuidados gerais de saúde físico-psico-social desses pacientes e seus familiares.

Para a consolidação deste estudo, destaca-se que uma limitação encontrada pelos enfermeiros diz respeito à desatualização dos cadastros dos pacientes na unidade de 


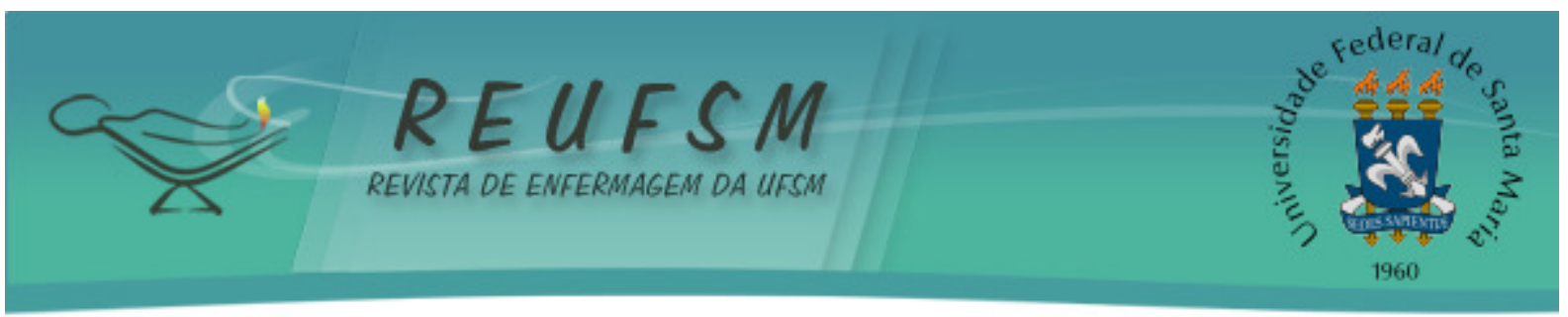

saúde, o que, de certa forma, dificultou a comunicação inicial entre profissional-paciente para a realização dos grupos.

\section{REFERÊNCIAS}

1. Ang SGM, Hui-Chen $\mathrm{H}$, Siah RJS, Hong-Gu H, Klainin-Yobas $P$. Stressors relating to patient psychological health following stoma surgery: an integrated literature review. Oncol Nurs Forum [Internet]. 2013 [acesso em 2015 set 01];40(6):587-94. Disponível em: https://onf.ons.org/sites/default/files/RJ7774QQ2410669G_first.pdf.

2. Instituto Nacional do Câncer (INCA). Estimativa 2016: Incidência de câncer no Brasil [Internet]. Rio de Janeiro; 2016 [acesso em 2016 maio 29]. Disponível em: http://www.inca.gov.br/estimativa/2016/sintese-de-resultados-comentarios.asp.

3. Ardigo FS, Amante LN. Conhecimento do profissional acerca do cuidado de enfermagem à pessoa com estomia intestinal e família. Texto \& Contexto Enferm [Internet]. 2013 outdez [acesso em 2016 maio 28];22(4):1064-71. Disponível em: http: / / www.scielo.br/scielo.php?script=sci_arttext\&pid=S0104-07072013000400024.

4. Batista MRFF, Rocha FC, Silva Júnior FJGD. Autoimagem de clientes com colostomia em relação à bolsa coletora. Rev Bras Enferm [Internet]. 2011 nov/dez [acesso em 2015 set 5];64(6):1043-7. Disponível em: http://www.scielo.br/pdf/reben/v64n6/v64n6a09.pdf.

5. Nascimento CMS, Trindade GLB, Luz MHBA, Santiago RF. Vivência do paciente estomizado: uma contribuição para a assistência de enfermagem. Texto \& Contexto Enferm [Internet]. $2011 \mathrm{jul} / \mathrm{set}$ [acesso em 2015 set 7];20(3):357-64. Disponível em: http://www.scielo.br/pdf/tce/v20n3/18.pdf.

6. Cervera DPP, Parreira BDM, Goulart BF. Educação em saúde: percepção dos enfermeiros da atenção básica em Uberaba (MG). Ciênc Saúde Coletiva [Internet]. 2011 [acesso em 2015 set 12];16(Supl1):1547-54. Disponível em: http: //www.scielo.br/pdf/csc/v16s1/a90v16s1.pdf.

7. Wild CF, Silveira A, Favero NB, Rosa EO, Guterres EC, Leal SDS. Educação em saúde na sala de espera de uma policlínica infantil: relato de experiência. Rev Enferm UFSM [Internet]. 2014 jul/set [acesso em 2015 set 15];4(3):660-6. Disponível em: http://cascavel.ufsm.br/revistas/ojs-2.2.2/index.php/reufsm/article/view/12397/pdf doi: $10.5902 / 2179769212397$.

8. Martins PAF, Alvim NAT. Perspectiva educativa do cuidado de enfermagem sobre a manutenção da estomia de eliminação. Rev Bras Enferm [Internet]. 2011 maio/abr [acesso em 2015 set 11];64(2):322-7. Disponível em: http://www.scielo.br/pdf/reben/v64n2/a16v64n2.pdf.

9. Brasil. Fundação Nacional de Saúde (FUNASA). Diretrizes de educação em saúde visando à promoção da saúde: documento base - documento I/. Brasília: Funasa; 2007. 70 p.

10. Freire P. Pedagogia do oprimido. 50 ed. Rio de Janeiro: Paz e Terra; 2011.

11. Freire P. Pedagogia da esperança: um reencontro com a pedagogia do oprimido. $15^{a}$ ed. São Paulo: Paz e Terra; 2007.

12. Freire P. Pedagogia da autonomia: saberes necessários á prática educativa. $49^{a}$ ed. São Paulo: Paz e Terra; 2014. 


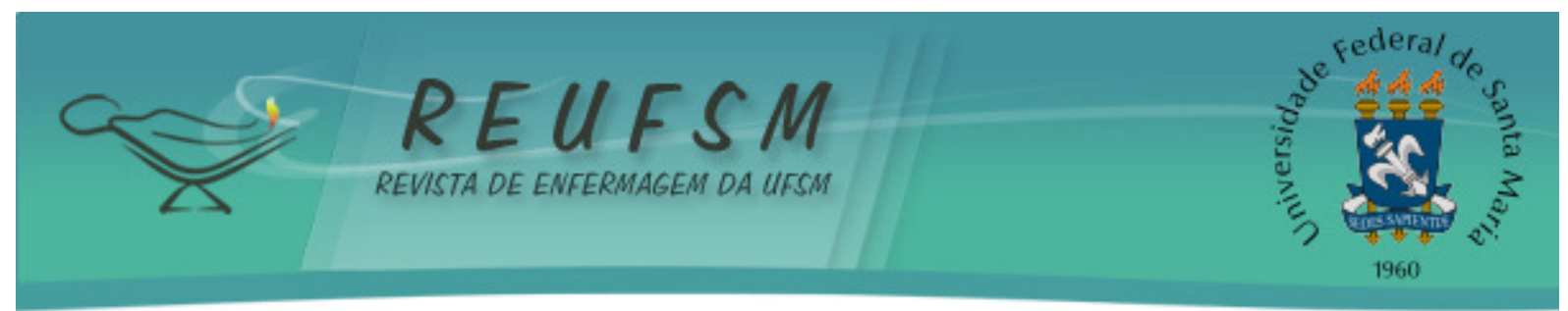

13. Coelho AR, Santos FS, Dal Poggetto MT. A estomia mudando a vida: enfrentar para viver. Rev Min Enferm [Internet]. $2013 \mathrm{abr} /$ jun [acesso em 2015 set 24];17(2):22-31. Disponível em: http://www.dx.doi.org/10.5935/1415-2762.20130021.

14. Nascimento CMS, Trindade GLB, Luz MHBA, Santiago RF. Vivência do paciente estomizado: uma contribuição para a assistência de enfermagem. Texto \& Contexto Enferm [Internet]. 2011 jul/set [acesso em 2015 ago 27];20(3):557-64. Disponível em: http://www.scielo.br/pdf/tce/v20n3/18.pdf.

15. Salles VEJA, Becker CPP, Faria GMR. The influence of time on the quality of life of patients with intestinal stoma. J Coloproctol [Internet]. $2014 \mathrm{abr} / \mathrm{jun}$ [acesso em 2015 ago 27];34(2):73-5. Disponível em: http://www.scielo.br/pdf/jcol/v34n2/2237-9363-jcol-3402-00073.pdf.

16. Salomé GM, Almeida AS, Silveira MM. Quality of life and self-esteem of patients with intestinal stoma. J Coloproctol [Internet]. 2014 out/dez [acesso em 2015 ago 27];34(4):231-9. Disponível em: http://www.scielo.br/pdf/jcol/v34n4/2237-9363-jcol-3404-0231.pdf.

17. Cetolin SF, Beltrame V, Cetolin SK, Presta AA. Dinâmica sócio-familiar com pacientes portadores de ostomia intestinal definitiva. ABCD Arq Bras Cir Dig [Internet]. 2013 jul/set [acesso em 2015 set 28];26(3):170-2. Disponível em: http: //www.scielo.br/pdf/abcd/v26n3/03.pdf.

18. Pereira APS, Cesarino CB, Martins MRI, Pinto MH, Gomes Netinho J. Associação dos fatores sociodemográficos e clínicos à qualidade de vida dos estomizados. Rev Latinoam Enferm [Internet]. 2012 jan/fev [acesso em 2015 out 18];20(1):93-100. Disponível em: http://www.scielo.br/pdf/rlae/v20n1/13.pdf.

Data de recebimento: 19/10/2015

Data de aceite: 06/06/2016

Contato do autor responsável: Cléton Salbego

Endereço postal: Avenida Nossa Senhora das Dores, 768, apto 202. Santa Maria, Rio Grande do Sul. CEP: $97.050-530$

E-mail: cletonsalbego@hotmail.com 